\title{
Alaska Sea Grant College Program Strategic Plan 2014-2017
}

\section{Vision}

Alaska will sustain its vibrant marine, coastal, and watershed ecosystems, with strong coastal communities and people who make decisions using science-based and traditional knowledge for the social and economic benefit of all Alaskans.

\section{Mission}

Alaska Sea Grant's mission is to enhance the wise use and conservation of Alaska's marine, coastal, and watershed resources, through research, education, and extension.

\section{Introduction}

Alaska's seas, coasts, and inland waters are vital to the culture and economy of the state, and are among the most productive and pristine in the nation. The state's 34,000 miles of coastline is over half of the entire shoreline of the United States. The federal exclusive economic zone (EEZ) off Alaska is more than twice the size of the land area of the state; 75 percent of the total continental shelf of the United States borders Alaska. Alaska's coastal habitats include a temperate rain forest and the only arctic ecosystem in the United States. These lands and waters nurture the most abundant populations of fish, shellfish, seabirds, and marine mammals anywhere in the nation.

\section{Marine Resources Underpin Alaska's Society}

Eighty percent of Alaskans live in coastal communities. Alaska's fisheries are fully allocated to commercial, recreational, and subsistence fisheries. The commercial fisheries provide more than half of all US seafood landings, and Alaska's pollock fishery alone accounts for about a third of all seafood production in the nation. Alaska contributed 95 percent of the total West Coast commercial harvest of highly valued Pacific salmon and halibut fisheries in 2011.

Commercial fisheries are the backbone of Alaska's coastal economy. The seafood industry (harvesting and processing) employs approximately 70,000 annually and provides the primary source of private income in many coastal communities. With close to 200 seafood processing facilities and nearly 800 processing permits ranging from vessels and land-based operators to direct marketers, Alaska's seafood industry is a significant contributor to the economy and is the state's largest private employer.

The harvest of wild resources including fish, shellfish, marine mammals, and marine plants by Alaskans for subsistence, sport, and personal use is an important source of food for residents. On average, rural Alaskans use a little over one pound of wild food per person per day, and in some regions the average per capita harvest can approach 600 pounds per person per year. Subsistence harvesting of seafood is central to the economy, lifestyle, and cultural values of Alaska Native communities.

The private, nonprofit salmon hatchery program is a substantial contributor to the total Alaska salmon harvest, producing millions of additional salmon for harvest and taking pressure off some wild stocks. To some degree the vast coastal resources are underutilized. The emergence of approved forms of mariculture offer new opportunities for community-based expansion of shellfish farming and also serve as each local community's barometer on the health of their adjoining marine and fresh waters. 
Coastal tourism accounts for much of the state's visitor industry. In 2012, nearly 1.8 million out-of-state visitors came to Alaska. Tourism supported approximately 45,000 peak-season jobs and contributed over $\$ 1.25$ billion in wages and benefits. Southeast Alaska received the majority of its visitors via cruise ships that delivered close to one million visitors to coastal communities in 2013, an increase over recent years. However, tourism occurs mainly between April and September, and the vast majority of tourists visit only the larger municipalities in each region, providing limited economic benefit to smaller, remote coastal communities.

Integrated with tourism is Alaska's lucrative sport fishing industry, providing opportunities in saltwater, rivers, and lakes throughout the state. In 2006, estimated spending on sport fishing topped \$316 million, during 35 million angler days. More than 20 percent of the expenditures were by nonresident anglers. The southcentral region dominates the sport fishing industry, receiving over 70 percent total angler effort. The charter fishing sector is very active, with more than 1,000 licensed halibut boats providing nearly 200,000 angler days of fishing in 2010.

While fisheries are a major contributor to the economy of coastal Alaskans, communities are economically challenged when stocks fluctuate or global markets change. Coastal communities across the state are in an ongoing quest to diversify their economies and to strengthen and improve traditional employment. New enterprises can include shellfish farming, food product development, wildlife/scenic tourism, and a range of small support and manufacturing businesses.

\section{A Changing Way of Life}

With the high dependence of the population on aquatic-based natural resources for employment, cultural heritage, and food security, Alaskans are directly influenced by climate change. Loss of sea ice, frequency and severity of storms, increased erosion and coastal inundation, changes in precipitation, diminishing permafrost, increasing stream temperatures, and changes in the abundance and distribution of subsistence resources are all presenting difficult challenges to Alaska's coastal and marine resourcedependent communities. Expansion of harmful algal blooms, marine invasive species, and ocean acidification are looming worries.

Climate change is transforming the Alaska way of life, and the Arctic is experiencing this most severely. With new transportation routes resulting from loss of sea ice, a sharp increase in vessel traffic to the Arctic has the potential for negative impact on subsistence resources and northern livelihoods, particularly felt by Alaska Native communities. Erosion due to storm damage and loss of ice barriers has several coastal communities contemplating evacuation routes or literally moving their villages. Marine mammal populations are shifting their patterns of migration, impacting the food security, safety, and way of life for Arctic hunters.

Physical hurdles that coastal communities in Alaska confront include their geographic isolation and lack of connection with each other. Cultural diversity is common; education levels are widely variable. The extreme high cost of fuel for power and heat is a formidable challenge for coastal Alaskans trying to develop successful businesses and traveling to critical policy meetings. Many Alaskans are not roadconnected to each other and depend on travel by plane or ferry. As digital interconnectivity improves, opportunities are opening to expand information sharing, education, and training.

\section{Alaska Sea Grant: Service to the State}

For more than four decades, Alaska Sea Grant has helped people understand, conserve, and wisely use Alaska's bountiful coastal and marine resources. We do this through an integrated program of research, 
education, and extension activities across the state delivered by Marine Advisory Program faculty and staff based in nine coastal communities.

Innovative research on salmon, funded by Alaska Sea Grant, is helping fisheries managers better understand long-term fluctuations in salmon populations. Information shared by scientists and resource managers at the Wakefield international scientific symposia has improved fishery management and led to greater understanding of high latitude marine ecosystems and communities.

Alaska Sea Grant has contributed to a well-trained workforce through its support of graduate students, by delivering professional development to teachers and seafood processors, and by providing statewide leadership in linking stakeholders, educators, and employers. We increase marine literacy among students and adults, supporting an Alaska-based marine education curriculum and connecting researchers to community needs and support.

Alaska Sea Grant's Marine Advisory Program efforts have yielded tangible results. The Alaska Young Fishermen's Summit continues to bring next-generation commercial fishermen face-to-face with political, industry, and regulatory leaders; hundreds of seafood processing personnel are trained in HACCP and deliver safe products around the world; coastal communities monitor for PSP and potential invasive species; and information and training delivered by Marine Advisory Program agents have contributed to higher value to fishermen's harvest and fewer fishing-related deaths.

Alaska Sea Grant is a partnership between the National Oceanic and Atmospheric Administration and the University of Alaska Fairbanks, Alaska's land and sea grant institution, and is administered by the School of Fisheries and Ocean Sciences. As one of 32 Sea Grant programs nationwide, Alaska Sea Grant is dedicated to helping Alaskans use marine resources wisely and sustainably into the future.

\section{Strategic Plan 2014-2017}

This strategic plan was developed under the guidance of the Alaska Sea Grant extension faculty and staff and our 25-member statewide Advisory Committee. The plan identifies Alaska Sea Grant's priorities in addressing critical coastal and marine issues in Alaska for the period 2014-2017 through seven goals developed under four National Sea Grant focus areas, and includes an eighth program management goal. The four national focus areas are:

- Healthy Coastal Ecosystems

- Sustainable Fisheries and Aquaculture

- Resilient Communities and Economies

- Environmental Literacy and Workforce Development

\section{Healthy Coastal Ecosystems}

\section{Situation}

Healthy ecosystems are the foundation of Alaska's way of life. For millennia, humans have been part of Alaska's coastal ecosystems, using seasonally abundant natural resources to meet their subsistence, cultural, and economic needs. Maintaining habitat quality is fundamental to supporting sustainable populations of marine life that are the focus of these subsistence and commercial uses. 
Climate change is changing the abundance and distribution of subsistence resources, presenting difficult challenges to Alaska's coastal and marine resource-dependent communities. Ocean acidification, expansion of harmful algal blooms, and potential marine invasive species are looming worries.

A variety of human activities pose threats to the sustained health of Alaska's coastal species, habitats, and communities. The harvesting of marine resources, physical and acoustic disturbance due to vessel traffic, military activities, and resource extraction can disrupt the migration, feeding, and breeding activities of species. Increased international shipping through Alaska's increasingly ice-free northern seas poses potential hazards.

Alaskans interacting with the coastal and marine environment have a high level of interest in understanding, conserving, and wisely using their local ecosystems. Alaska Sea Grant will build partnerships and provide science, education, and outreach to Alaskans as they address these critical issues while bringing traditional knowledge and input back to researchers.

\section{Goal 1: Healthy marine, coastal, and watershed ecosystems in Alaska}

\section{Strategies}

- Coordinate, sponsor, and advise on best practices of community-based monitoring to increase understanding of changes to the environment and contribute to the knowledge base. Coordinate community-based monitoring.

- Monitor for the introduction of marine invasive species, improve basic understanding of impacts from invasive species, and participate in mitigation.

- Develop and advise on best practices for commercial operators or boaters interacting with wildlife.

- Sponsor and collaborate in research related to coastal ecosystem services and management. Provide venues for researchers to engage local residents in development of their projects and presentation of results.

- Provide decision makers with science-based information that can be used in developing policies governing use and conservation of resources.

- Enhance understanding of and encourage participation in international, federal, and state policymaking related to marine resource management and potential impacts to coastal resources from human-induced activities.

\section{Outcomes}

- Coastal residents will use science and traditional knowledge to develop and implement protocols to detect environmental anomalies and to monitor or initiate response, and will have baseline data needed to observe change.

- Concerns of coastal Alaskans will be incorporated into resource agency and policy discussions and policies will be developed incorporating science and traditional knowledge.

- Negative human interactions with marine wildlife will be reduced through educational programs to mitigate impacts of intentional and unintentional harassment, shipping noise, entangling debris, strandings, bycatch, introduced diseases, oil spills, and other potential hazards.

- Researchers will incorporate local and traditional knowledge into their research design and local residents will have access to results of relevant research. 


\section{Sustainable Fisheries and Aquaculture}

\section{Situation}

More than 150 coastal communities from Ketchikan to Kotzebue depend on the harvest of fish and other marine resources and seafood processing to feed their families and sustain local economies. Commercial fishing and seafood processing are the largest private employers in the state, employing approximately 70,000 Alaskans and non-Alaskans annually. Subsistence harvest and the culture of sharing resources among families and communities are found in Alaska Native as well as non-Native traditions throughout Alaska. Recreation and guided sport fishing activities occur along Alaska's expansive coastline, in lakes and rivers.

Fluctuations in fish and shellfish populations impact food security and economies. Predation, depredation, and competition with fisheries by growing marine mammal populations require innovative measures to maintain sustainable fisheries. Stress on marine ecosystems from climate change, annual and decadal stock fluctuations, and management actions for allocation purposes challenge fishery managers, harvesters, and seafood businesses in ensuring resource sustainability. Harmful algal blooms impact commercial shellfish farmers and impact personal harvest opportunities.

Alaska's waters provide more than 50 percent of America's fisheries landings each year. Changing market demands and global competition are challenges to the industry. Fishing access has been privatized in Alaska, and managers are designing new access programs to meet increasingly complex conservation and management objectives. Alaska harvesters seek to participate effectively in the process.

The Food Safety Modernization Act (FSMA) aims to ensure the safety of the US food supply by focusing on preventing contamination rather than responding to it. FSMA makes HACCP-type preventive controls the norm in all food processing facilities. Alaska's seafood processors are ahead of the curve with regard to HACCP, but must continue to be vigilant to respond to stricter preventive controls for their operations.

Seafood quality and safety is an ongoing issue for commercial and personal use food processors. Alaska's processing industry with nearly 200 land-based facilities is remote, seasonal, and diverse with an everchanging workforce. Small and mid-sized processors operating in remote locations face limited training support, limited resources for product analysis, and high energy and production costs. Stricter regulatory requirements for discarding fish waste are driving forces for the Alaska seafood industry to obtain value from discards. Development of viable byproducts that meet today's emphasis on "green" manufacturing can also increase value of the fishery.

Shellfish aquaculture is a growing industry in Alaska that will provide economic diversification for a number of coastal communities. Alaska shellfish farmers need support for efficient operations and response to potential environmental threats such as disease and increasing ocean acidification.

\section{Goal 2: Safe, sustainable, and sought-after seafood products that minimize waste and provide a stable source of food and strong economic returns to Alaska communities.}

\section{Strategies}

- Train seafood processors and fishermen in safety and quality. Create curriculum and training materials that can be available via distance delivery.

- Provide lab analysis and/or applied research to support seafood and other food producers in developing new products or processes or reducing waste. 
- Develop business plans and research marketing information for small or mid-sized seafood processors.

- Provide training and technical assistance to fishermen looking to directly market and/or process their fish or shellfish.

- Develop and offer leadership training to support succession in the seafood harvesting and processing industry.

- Inform Alaskans about food safety and security for subsistence, sport, personal, and commercial users.

- Participate in the Fisheries, Seafood and Maritime Workforce planning effort and utilize industry guidance in establishing priorities and appropriate actions by Alaska Sea Grant.

- Research new testing techniques and inform Alaskans about paralytic shellfish poisoning and risks from other harmful algal blooms.

\section{Goal 3: Healthy and sustainable commercial, sport, and subsistence fisheries and shellfish farming as a long-term economic force in Alaska.}

\section{Strategies}

- Sponsor and collaborate in critical fisheries research; encourage the engagement of stakeholders in planning, design, and implementation of research and in collaborative research among fishermen, managers, and scientists.

- Increase understanding by fishermen, community members, and state policy makers of implications of climate change and other changes on fishery resources through involvement in research and access to results.

- Sponsor research and increase understanding by managers and stakeholders of community impacts from various fisheries management strategies.

- Collaborate with fishermen and other users to research methods to reduce interactions with marine mammals.

- Train and inform fishermen and other stakeholders to enhance participation in the public process of fisheries management and habitat conservation.

- Inform subsistence and sport fishermen on seafood safety, harvest issues, and best practices.

- Investigate feasibility and pathways to develop new fisheries in Alaska through support of research, regulatory review, product forms, etc.

- Research and transfer information related to a secure source of shellfish seed supply for farmers, to improve farming practices and to maximize and diversify shellfish production.

- Participate with state and federal regulatory agencies and committees to contribute to the sustainability of fisheries and shellfish industries.

\section{Outcomes}

- Fishermen and shellfish farmers have an understanding of their markets and product forms, enabling them to develop strategies that optimize the results of their effort.

- Seafood processors, particularly small or new companies, will have the information needed to optimize the safety, quality, and profitability of their products. 
- Seafood processing companies will adopt new processes that conserve energy, reduce waste, and improve productivity.

- Subsistence, sport, and commercial fishermen; processors; charter operators; and consumers will have access to information about handling their seafood to preserve quality and safety.

- Shellfish operators will demonstrate an understanding of the business and operation as they develop and maintain their aquaculture operations. Shellfish farms will increase in number or size and will use best management practices.

- Fishing communities will retain or recapture fishing power to maintain commercial fishing as an economic engine.

- Fisheries managers will have access to information needed to support the sustainable management of fisheries in Alaska.

- Fishermen and fisheries managers will have access to the best available knowledge of impacts of climate change to their resource, allowing them to plan for the future.

\section{Resilient Communities and Economies}

\section{Situation}

Over 70 percent of Alaska's 700,000 residents live along its coastline. Less than 10 percent of coastal Alaska communities are connected by road; most are accessible only by boat or airplane. This "lack of connection" is a defining feature of Alaska's coastal communities and often is relished by its residents, but it also creates economic and educational challenges.

Alaska's coastal communities are culturally diverse; 90 languages are spoken in the Anchorage School District. Many rural communities are over 50 percent Alaska Native and bring traditional knowledge that provides a historic basis to understand the recent changes in Alaska's natural resources.

In small towns, businesses such as seafood processing and tourism may be only marginally profitable. High cost of electrical power and fuel for heat and transportation in small Alaska communities often defines the economic feasibility of businesses, including fishing operations and shore-based coastal industries. For example, the per-kilowatt electricity cost in the Yukon Delta is about five times that in Anchorage, and gasoline in remote locations typically is two to three times as costly as in the rest of the country. Coastal businesses need tools and assistance to understand production efficiencies and energyreduction strategies, to reduce operational overhead.

Coastal Alaska is experiencing impacts from climate change firsthand. Loss of sea ice in the Bering Sea reduces access by subsistence hunters to marine mammals and no longer provides a dependable buffer to winter storm waves. Coastal erosion is accelerating in many northwestern Alaska villages, and communities across Alaska are working to understand how to adapt to a rapidly changing physical environment.

Critical to the well being of coastal Alaska communities is a diverse economic base. Commercial fishing remains the economic backbone of many coastal communities, but fluctuations in stocks and market demand challenge the industry. Tourism, charter boat recreation, handicrafts, vessel repair and maintenance, air charter services, small seafood processing, shellfish farming, and other coastal service businesses such as harbors, docks, and freight forwarding are important sources of jobs and income. Public sector occupations such as fisheries managers, teachers, and other professionals also provide 
employment, and the state's young people need to be trained and educated for these and many other career opportunities.

Proposed and ongoing mineral extraction, and onshore and possibly offshore oil and gas drilling, are leading to hard public policy and business decisions in Alaska. Balancing responsible extractive resource development with the viability of renewable resources is a constant tension for residents, industries, and regulators.

Alaska drowning and accident rates are eight times the national average, and drowning is the second leading cause of death for Alaska's children. Subsistence harvesters in rural areas are at greatest risk. However, annual loss of life at sea in Alaska has been trending downward, due in part to mandatory and voluntary marine safety training. Responding to additional training requirements, expanded vessel standards, and newly mandated safety compliance programs will increase costs and time demands on Alaska fleets in the next few years.

Food security and food safety are growing concerns for coastal communities, both rural and urban. Some areas of concern are food-borne illnesses from high levels of home harvesting and food preparation, high levels of obesity, and frequently used species that are in decline or impacted by human activities. Access to the financial resources for equipment to harvest food is a food security concern.

\section{Goal 4: Vibrant coastal communities with strong and diverse economies related to healthy marine and freshwater resources.}

\section{Strategies}

- Train and provide technical assistance to new or expanding coastal businesses such as shoreside vessel support services, seafood processing, charter fishing, and ecotourism operations.

- Provide leadership training for youth and adults related to natural resource careers and participation in the public process.

- Serve as the point of access to university and other educational programs that lead to career opportunities in communities.

- Develop programs that identify and resolve impediments to new entry to address the graying of the fleet and promote success in Alaska's community-based fisheries.

\section{Goal 5: Community residents with skills and knowledge to adapt to coastal hazards and environmental change.}

\section{Strategies}

- Inform communities about coastal hazards, ocean acidification, and climate change, and related policy issues and engage them in planning to reduce vulnerability.

- Partner with coastal monitoring programs to make monitoring information more accessible and useful to coastal residents and groups.

- Coordinate, teach, and participate in oil spill and shipping accident prevention and response preparedness in communities, particularly in Prince William Sound and the Arctic.

- Monitor and inform the Alaska public about harmful algal bloom (HABs) events and marine invasive species status.

- Train and inform Alaskans about marine safety to reduce fatalities and injuries related to boating, travel on sea ice, exposure to weather, and other hazards. 


\section{Outcomes}

- Coastal communities will continue to diversify their economies and will demonstrate an understanding of how to look for and develop new opportunities.

- Local residents and community leaders will demonstrate an understanding of the considerations in developing and maintaining rural tourism operations.

- Local residents will increasingly be employed as researchers, technicians, or monitors.

- Coastal residents will understand their potential personal vulnerability to climate change and will develop adaptation strategies. Coastal communities will take action to adapt to anticipated changes.

- Public safety and other officials will know the risks and hazards of their regional environment and how to respond.

- Community members along the Aleutian and arctic shipping routes will understand shipping risks and develop appropriate response capabilities.

- Coastal communities will be prepared to respond to oil spills, and to respond to search, rescue, and loss of life situations.

- Marine and coastal boating accident and fatality rates will decrease because boat operators will have an increased awareness of how to prevent accidents.

- Boaters will safely enjoy more of the coast because they have accurate information on hazards and safe travel routes.

\section{Environmental Literacy and Workforce Development}

\section{Situation}

Alaska's marine and coastal resources are among the most pristine and extensive in the world. Annually, close to two million visitors join 700,000 state residents in enjoying these resources through recreational activities. Understanding Alaska's resources increases the public's enjoyment and conservation of this unique environment.

Alaska residents face ongoing and complex decisions about the conservation, use, and management of marine and coastal watershed resources. Changes to the environment, especially in relation to a changing climate, further complicate these decisions. Alaska's economic future depends on sustainable management and development of its natural resources. This requires an environmentally literate citizenry.

The graying of the fleet and coming retirements of experienced fisheries managers and seafood processors challenge the succession in these vital industries. The State of Alaska and University of Alaska system are engaged in the development of a statewide Fisheries, Seafood and Maritime Workforce Development Plan. Appropriate training and support is vital as the next generation of harvesters, managers, processors, technicians, and maritime personnel take the helm of Alaska's industries. Alaska Sea Grant's role in workforce development includes leadership in bringing employers, educators, and stakeholders together to identify and act on workforce strategies.

At Alaska Sea Grant, education includes formal education, which takes place in school settings from kindergarten through graduate school, and informal education, which takes place in a variety of afterschool, summer camp, and other settings for youth as well as in field settings and regional science centers for lifelong learners. During the last five years, research has characterized and documented the 
importance of informal science education, including citizen science programs and ocean and climate literacy for adults and youth. Best practices revealed by this research give Alaska Sea Grant the opportunity to provide leadership in professional development training to increase and consistently measure the impact of Alaska informal marine educators, including Marine Advisory agents, on their audiences.

Alaska Sea Grant has over the last four years been a partner in the NSF-funded COSEE Alaska project. Support will end in August 2014 when NSF will dissolve COSEE nationwide. Meanwhile, NOAA and Sea Grant marine educators have helped define ocean and climate literacy principles, much of which has been incorporated into national K-12 science standards known as the Next Generation Science Standards.

During the same period, Alaska Sea Grant has helped draft the Alaska Environmental Literacy Plan. With the COSEE Alaska focus on integrating Alaska Native knowledge with Western science, Alaska Sea Grant has emphasized engaging Alaska Natives in science education and promoting the recognition of Alaska Native heritage in relation to stewardship of natural resources for all Alaska students. In 2015 the Alaska Department of Education and Early Childhood Development will begin to revise its science standards, providing an opportunity to improve the emphasis on marine and aquatic education and stewardship since the 1993 standards were adopted. The impact of Alaska Sea Grant curriculum and K-12 programs depends on participation in this process and alignment with the new standards.

\section{Goal 6: An environmentally literate public of Alaska residents and visitors.}

\section{Strategies}

- Inform Alaskans about important and current environmental issues with science-based information and traditional knowledge.

- Inform visitors to Alaska about the impacts in our state from climate change and potential impacts of ocean acidification.

- Produce books, publications, videos, news releases, websites, social media, and other educational tools that provide information to Alaskans and visitors about the state's marine and coastal environment.

- Engage Alaskans in educational experiences throughout their lifetime that increase their environmental literacy.

- Assist researchers in their design of science outreach and broader impacts.

- Develop and deliver community and educator/student involvement in the science carried out on the R/V Sikuliaq.

- Participate in the achievement of state environmental literacy through involvement in design of standards and support for Alaska teachers.

- Enhance the use and circulation of the Alaska Sea Grant Seas and Rivers curricula.

Goal 7: A workforce of highly skilled Alaskans in the diverse marine, fisheries, seafood, and maritime occupations in the state.

\section{Strategies}

- Lead and participate in the statewide Fisheries, Seafood and Maritime workforce development planning and implementation efforts to identify priorities and meet industry needs. 
- Engage industry members and state agencies in developing strategies to encourage more Alaskans to enter this workforce.

- Collaborate with educators and employers to make training, educational opportunities, and internships widely available across the state and increase awareness of these opportunities among Alaskans.

- Target underserved populations in our state, such as rural and Alaska Native, in these occupations.

\section{Outcomes}

- Interactions between researchers and educators, students, and the public will be increased.

- Alaskans will increase their involvement in environmental stewardship.

- Alaskans will have increased knowledge of marine resource issues so that they can make better decisions.

- School districts will increase their adoption of marine education materials. In particular, the use of Alaska Seas and Rivers curriculum will increase statewide.

- Alaska's youth will be introduced to fisheries, seafood, and maritime opportunities prior to making career decisions. An increased number of youth, particularly from underserved populations, will pursue this educational pathway.

- The Alaska coastal workforce in fisheries, seafood processing, and maritime trades will have increased vocational training support that is accessible and relevant to the changing needs of each industry.

- Qualified Alaska residents will increasingly fill maritime, fisheries, and seafood processing positions in coastal communities.

\section{Goal 8: Strategic program management ensuring Alaska Sea Grant is responsive and forward thinking.}

\section{Situation}

Alaska's residents, economy, and livelihoods are deeply reliant on coastal resources, creating a pressing need for practical solutions to problems faced by coastal communities. Alaska Sea Grant's integrated effort of research, education, and Marine Advisory Program extension is unique in the state. The following strategies support this approach used to tackle the diverse, complex, and interconnected issues identified in this plan.

\section{Strategies}

- Alaska Sea Grant will continually engage with Alaskans on priority marine resource and coastal issues and be flexible and responsive to programmatic changes as needs in our state change.

- Alaska Sea Grant will partner and collaborate with state and federal agencies, tribal organizations, Alaska Native corporations, the private sector, NGOs, and other university programs to efficiently and effectively address issues in the state. We will use our statewide network to focus on local, regional, and statewide issues reaching for national impact when our contribution will be valuable.

- We will support the University of Alaska Fairbanks and the School of Fisheries and Ocean Sciences through the common goal of bringing university resources to Alaska's communities to ensure healthy marine and coastal resources. 
- Alaska Sea Grant will actively seek to leverage federal and university funds, increase the donation base, and seek external funding to provide the program with additional resources to address Alaska Sea Grant's goals.

- Alaska Sea Grant will seek and implement approaches to more effectively integrate research with extension across all of our focus areas.

- Students who are supported by Alaska Sea Grant will be clearly identified and will understand the overall goals and work of Alaska Sea Grant.

- Alaska Sea Grant will maintain updated and broad tools of communication that meet the learning styles and technical skills of a diverse Alaska population.

- Alaska Sea Grant will provide leadership, facilitation, science synthesis, coordination, and other support to communities to help them make difficult decisions across all focus areas.

- Alaska Sea Grant will provide professional development opportunities for faculty and staff in areas of subject content and effective modes of delivery.

\section{Alaska Sea Grant Performance Measures for 2014-2017}

National Sea Grant defines national performance standards related to all Sea Grant program activities. These are integrated below with four additional performance standards relating to Alaska Sea Grantspecific activities.

\section{Focus Area: Healthy Coastal Ecosystems}

1. Number of tools, technologies, or sources of information used by our partners/stakeholders to improve ecosystem-based management.

2. Number of ecosystem-based approaches used to manage land, water, and living resources in coastal areas as a result of Alaska Sea Grant activities.

\section{Focus Area: Sustainable Fisheries and Aquaculture}

3. Number of fishermen, seafood processors, and aquaculture industry personnel who modify their practices using knowledge gained in fisheries sustainability and seafood safety as a result of Alaska Sea Grant activities.

4. Number of communities that modify marine subsistence harvest practices using science-based and traditional ecological knowledge, wild food safety information, and sustainable harvest levels assisted by Alaska Sea Grant activities,

5. Percentage of commercial salmon harvesters employing marine mammal gear entanglement avoidance strategies who participated in Alaska Sea Grant activities.

\section{Focus Area: Resilient Communities and Economies}

6. Number of communities that implement sustainable economic and environmental development practices and/or policies (e.g., working waterfronts, energy efficiency, climate change) as a result of Alaska Sea Grant activities.

7. Number of communities that implement hazard resiliency practices to prepare for, respond to, or minimize coastal hazard events as a result of Alaska Sea Grant activities. 


\section{Focus Area: Environmental Literacy and Workforce Development}

8. Number of Alaska Sea Grant-facilitated curricula adopted by formal and informal educators.

9. Number of people engaged in Alaska Sea Grant-supported informal education programs.

10. Number of employees who remain in their jobs and/or advance in their careers as a result of professional development by Alaska Sea Grant.

11. Number of Alaska Sea Grant-supported graduates who become employed in a career related to their degree within two years of graduation.

\section{Cross Cutting Performance Measures}

12. Economic (market and non-market; jobs and businesses created or retained) benefits derived from Alaska Sea Grant activities.

13. Number of peer-reviewed publications produced by the Alaska Sea Grant network, and number of citations for all peer-reviewed publications from the last four years. 